\title{
CARIBISCHE BEELDEN I-V
}

DOOR

\section{P. WAgenAar HUMMELINCK}

\section{HUISJE MET WRIJFSTEEN OP ARUBA}

1 Februari 1885: Een Zondag van de 12 dagen die de „Nederlandsch West-Indische Expeditie" op Aruba doorbrengt - een rustdag, welke de geoloog KARL MARTIN gebruikt om de ,plantage" Fontein en omgeving nader te verkennen.

Het woonhuis blijkt erg vervallen. Er staan een paar wrakke tafels en banken en aan de daksparren hangen, in een schilderachtige wanorde, allerlei huishoudelijke werktuigen ... ,das wichtigste von allen Instrumenten ist aber unstreitig der sogenannte kiesteen (offenbar vom holländischen keisteen abkünftig), auf dem Mais und Kaffee gerieben wird, in einer Weise, wie sie auch bei unsern Vorvätern statt hatte. Auf einem Baumstumpfe von Tischhöhe, dessen oberer Theil mehrfach gegabelt ist, oder auch einfach an der Erde liegt nämlich ein annähernd flacher Block, welcher als Unterlage dient, darauf der Reibstein, mit dessen Hilfe die Frau des Hauses ihren ,,grossen” (Zea) und ,,kleinen Mais" (Sorghum) zerkleinert .... Der aus dem Mehle gefertigte Teig wird alsdann auf einer Eisenplatte geröstet und liefert das Gebäck, welches den Namen arepa (von „,kleinem Mais” gebacken) oder katjapa (von ,,grossem Mais”' gebacken) trägt, und deren Erstgenanntes das Hauptnahrungsmittel des Volkes bildet" 1 ).

Een dergelijke wrijfsteen werd gevonden bij een vervallen koenoekoe-huisje in Rooi Arikok. Het zware blok kwartsdioriet met de kom waarin vroeger de kleine mais werd fijngewreven (de piedra di mula) lag aán de voet van twee sterke gaffels (fig. 2),

1) K.MARTIN : Bericht über eine Reise nach Niederländisch West-Indien, I, 1888 (p. 131, plaat XIV fig. 23). Zie fig. 15. - Het Augustus-blad van Aruba 1956 - de kalender van de Lago Oil \& Transport Co., welke twaalf reproducties bevat van kleurenfoto's van Faces of Aruba - toont een vrouw die bezig is kleine-mais fijn te wrijven: "Stone flour-mills like this ... were once a common household item". 
waarop het gemakkelijk weer kon worden gelegd in de positie waarin het vroeger was gebruikt (fig. 1) ${ }^{1}$ ). De nog aanwezige wrijfsteen zelve (de manga) - een koraalsteen ${ }^{2}$ ) - kon dan, in een iets voorovergebogen houding, met twee handen krachtig worden gebruikt.
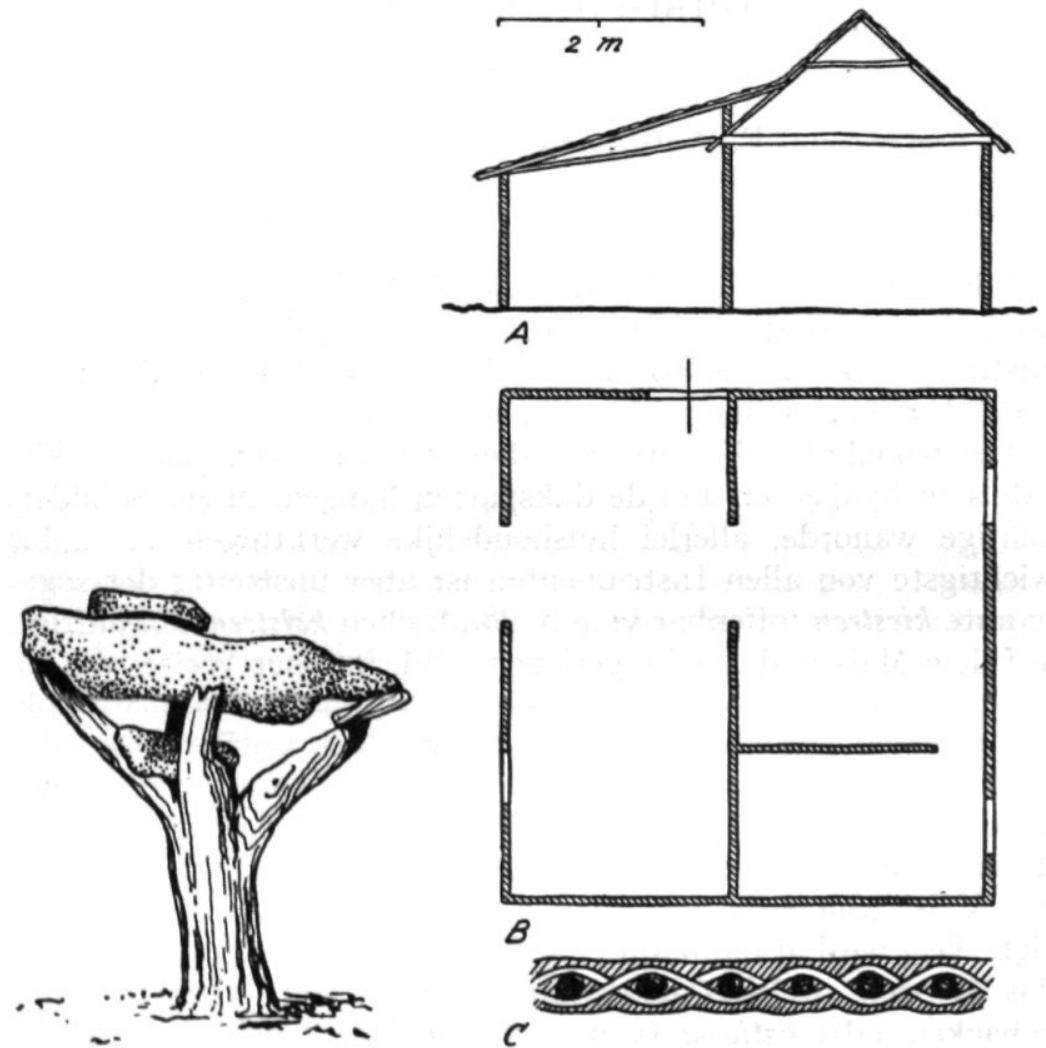

Fig. 15. Een , kiesteen”, waarop mais en koffie werden fijngewreven, zoals door MARTIN in 1885 op de plantage Fontein (Aruba) werd aangetroffen. Fig. 16 Schematische doorsnede (A) en plattegrond (B) van het gevlochten huisje in Rooi Arikok, waarbij de wanden met een mengsel van zandig leem en gras zijn dichtgesmeerd (C). Zie fig. 1 en 3.

Het huisje waarbij de piedra di mula stond opgesteld behoort tot een type, waarvan vroeger in Aruba - en ook op het naburige vasteland, maar niet op Curaçao en Bonaire - veel voorbeelden waren te vinden.

1) De foto's van fig. 1 en 3 werden gemaakt door K. J. van GAALEN, in wiens gezelschap deze plaats op 5 Mei 1955 werd bezocht.

2) Er zijn ook manga's van kwartsdioriet bekend. 
Het bouwplan is, mede door het ontbreken van een stookplaats, wel uiterst eenvoudig: Een rechthoekige ruimte welke door een schot in twee ongelijke delen is verdeeld, met (aan de zuidzijde) een aanbouw onder een zijvleugel van het dak (fig. 16A-B).

Het geraamte van het huisje wordt gevormd door een aantal rechtopstaande palen en dwarsbalken, met daarboven dakspanten die met cactushout zijn gedekt. De wanden bestaan uit een stevig vlechtwerk dat met een mengsel van grofzandig leem en gras is bestreken en met een laagje kalk gesausd (fig. 16C) ${ }^{1}$ ).

Merkwaardig is de ligging van de deur: aan de zijkant, tegenover de wrijfsteen (fig. 16B). Het is mogelijk dat de deur aan de voorzijde en de kleine raampjes, die met gezaagd hout zijn afgetimmerd, er pas later zijn ingemaakt.

$$
\text { II. DE ,MARTELLO TOWER" OP BARBUDA }
$$

De Martello Tower is meestal het eerste dat men van het lage kalksteeneiland Barbuda ziet, als men van Antigua naar het Noorden vaart.

Het bouwwerk dat men boven de strandvegetatie ziet uitsteken (fig. 4) doet denken aan de ruine van een suikermolen - bekend beeld oṕ de kleine West-Indische eilanden. Maar de vorm is plomper en de ligging vreemd, vooral als men weet dat er op Barbuda nooit suikerriet in een hoeveelheid van enig belang werd verbouwd.

Bekijken wij deze toren van dichtbij, dan zien wij, aan de rand van een omstreeks $3 \frac{1}{2}$ meter hoog terras dat nog geen 40 vierkante meter groot is, zware kantelen. Zij liggen niet om de toren heen, zoals wij zouden verwachten, maar zijn er alleen aan de zeezijde tegen aan gebouwd (foto 5). Alleen van dit terras is het binnenste van de toren te bereiken.

De toren is omstreeks 13 meter hoog en 3 (van boven) tot 5 meter (beneden) dik. Op drie verschillende hoogten zien wij een aantal kijkgaten, waarvan wij de middelste serie (omstreeks 6 me-

1) Men vergelijke hetgeen over primitieve woningbouw gezegd wordt door NicolaAs van MeEtéren: Volkskunde van Curaf̧ao, 1947 (p. 20-21). Volgens zijn opgave wordt voor het vlechtwerk meestal mata galinja (Acacia villosa) gebruikt. In dit geval kon in staanders en tenen alleen hout van een Leguminoos en van een Malvacee of Sterculiacee worden herkend, terwijl in het gebruikte mengsel van grassen slechts de op de Nederlandse Antillen algemeen voorkomende soort Anthephora hermaphroditica opviel. Het dak was afgedekt met gespleten houtcylinders van kadoesji (Cereus repandus) en datoe (Lemaireocereus griseus). 
ter hoog) misschien wel schietgaten mogen noemen. Onder deze middelste rij - de grootste gaten - bevindt zich aan de binnenzijde een rand waar de uiteinden van zware vloerbalken zijn ingemetseld geweest. De resten van deze houten balken kan men nog zien, als men van boven door het kegelvormige lijf van de toren naar beneden kijkt.

Dicht bij de toren, aan landzijde, bevindt zich een oude, ommetselde put, welke reeds op minder dan één meter diepte het op smaak zoete grondwater bereikt.

Betwijfeld mag worden of dit bouwwerk ooit veel strategische waarde heeft gehad. Misschien was dit ook niet nodig en kon het door het maken van een ontzagwekkende indruk reeds grotendeels aan zijn doel beantwoorden. Barbuda genoot vroeger slechts als slaven-plantage enige bekendheid. Thans bezit het alleen nog maar enige faam omdat de gezondheidstoestand van de 1200 personen tellende bevolking de aanwezigheid van een medicus blijkbaar overbodig maakt, en om de ordening van de samenleving volgens een aantal richtlijnen, die dateren uit de tijd toen het eiland nog in het bezit was van de familie CoDRINGTON.

De Martello Tower ligt omstreeks 180 meter van de kust: een breed zandstrand, dat zich als een ononderbroken wit lint van meer dan 25 kilometer lengte langs de zuid- en de westkant van Barbuda uitstrekt. Bodem en vegetatie wijzen er echter op dat de toren vroeger veel dichter bij het water heeft gestaan. Hij lag toen misschien niet meer dan 80 meter van de landingsplaats door het aandoen waarvan men Codrington Village - het enige dorp, want hierbuiten mochten vroeger geen kleurlingen wonen en zij doen het nu nòg niet! - op de snelste wijze kan bereiken: Bijna 50 kilometer van de kust van Antigua (55 km van St. John) en dan nog $5 \frac{1}{2} \mathrm{~km}$ over land ${ }^{1}$ ).

De Martello Tower heeft thans nog slechts een zekere functie als herkenningsteken voor zeevarenden. Van het terras af kan men nu nog langs een wrakke ladder de top bereiken, waar, aan een schuin-opstaande paal, seintekens zouden kunnen worden bevestigd.

Door de bevolking wordt de Martello Tower voor een oud

1) Wil men het schip laten aanleggen aan de steiger van Codrington Village, dan moet men eerst nog $15 \mathrm{~km}$ langs het westerstrand naar het Noorden en dan, door een grote lagune, deze afstand weer grotendeels terug. Maar die lagune binnenkomen kan men alleen als de boot niet veel meer diepgang heeft dan één meter! Dit was althans zo tijdens het bezoek van schrijver in Juli 1955. 


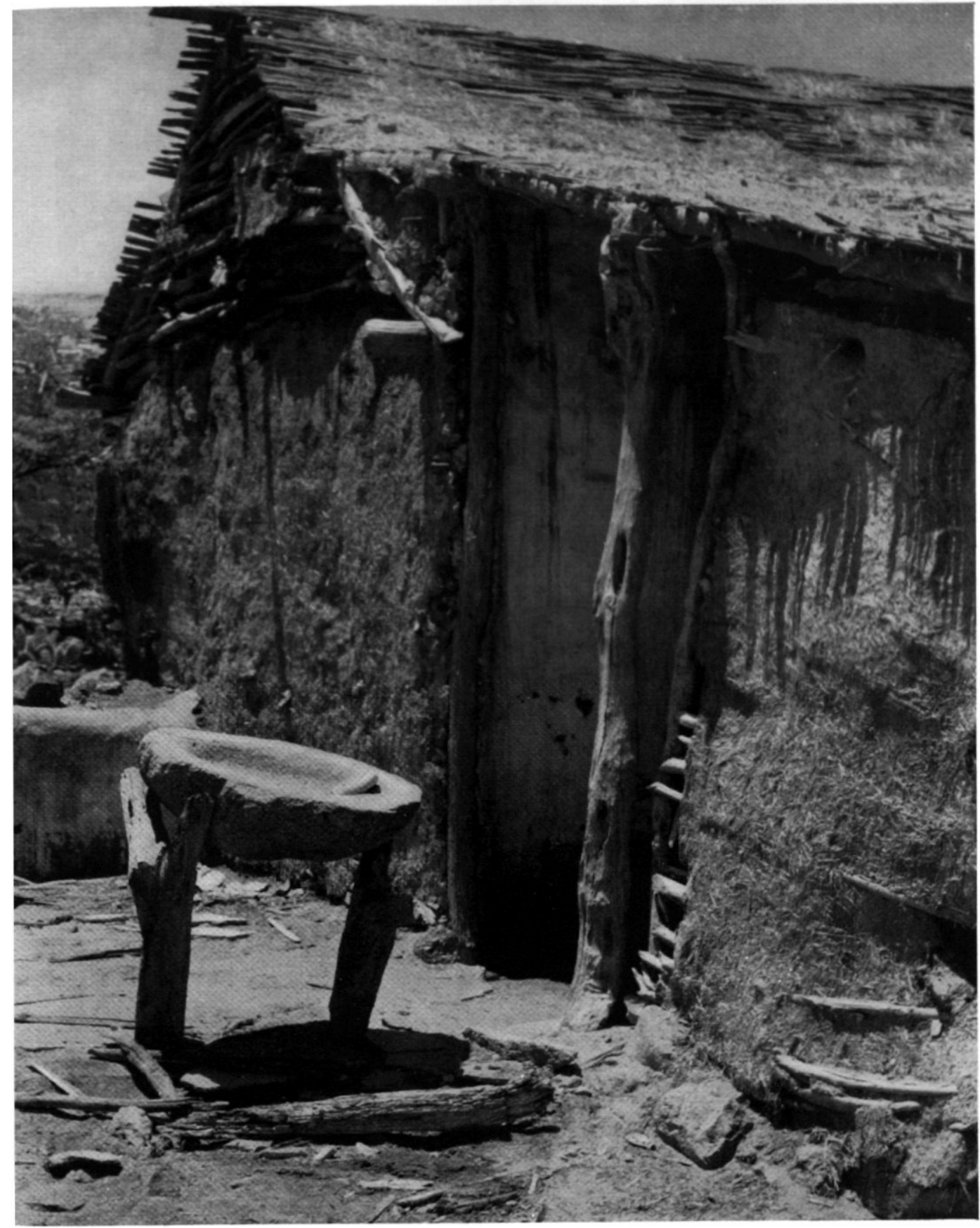

Fig. 1. Een oude wrijfsteen, opgesteld naast een vervallen huisje bij Rooi Arikok op A r u b a. 


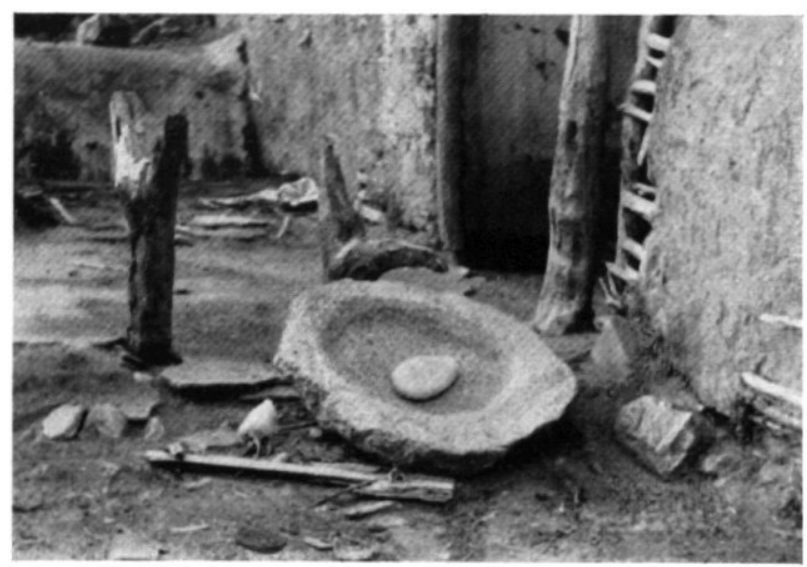

Fig. 2. De „piedra di mula”, met de ,,manga" er nog in, zoals hij werd gevonden.

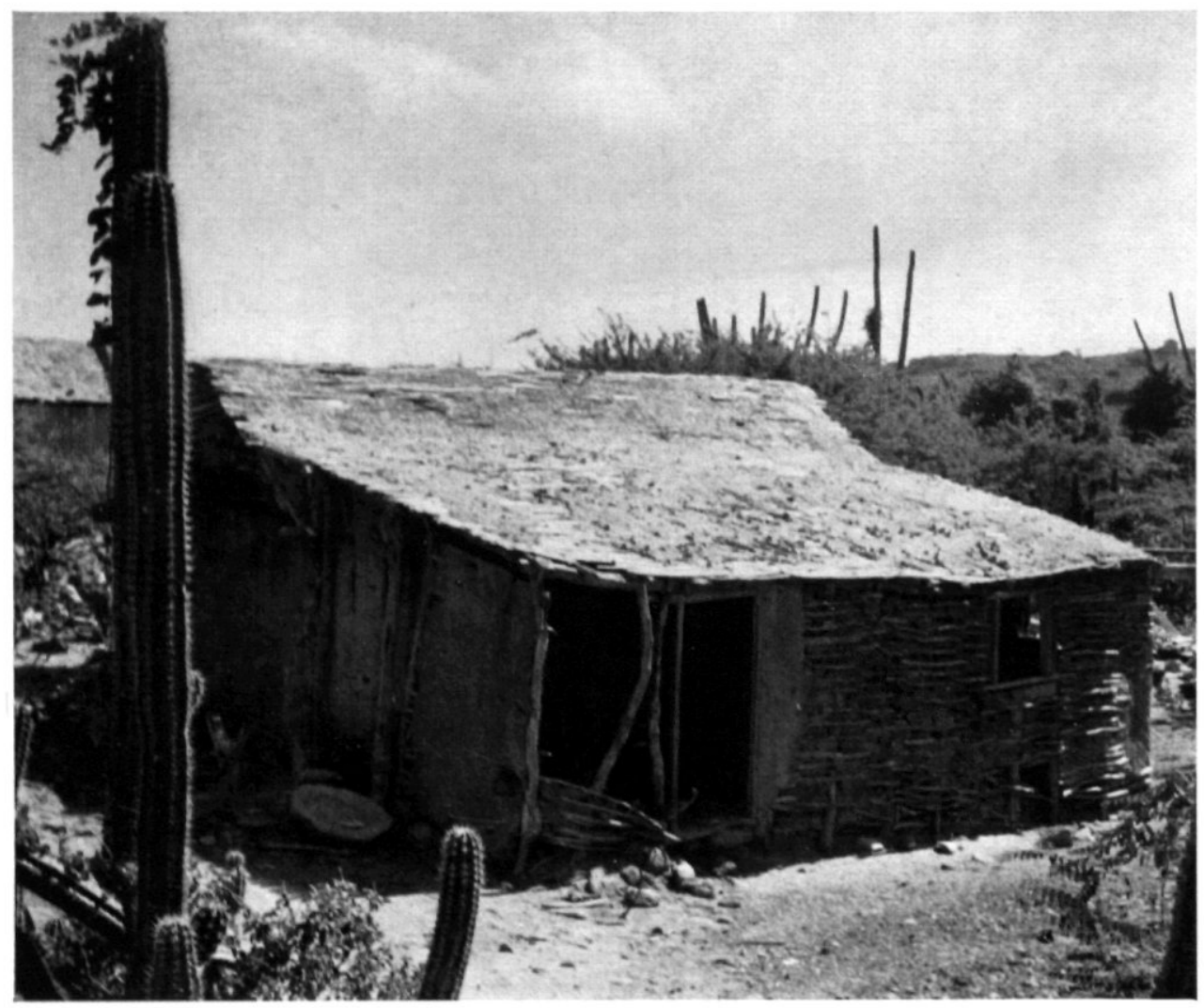

Fig. 3. Het gevlochten huisje, afgedekt met cactushout en dichtgesmeerd met een mengsel van zandige leemgrond en gras. 
Spaans fort gehouden, hoewel er over oorsprong en ouderdom niets bekend is. Het is opgetrokken uit koraal-zandsteen (niet uit de kalksteen waar het eiland grotendeels uit bestaat), waarbij reparaties veelal met kleine baksteentjes (z.g. ijzersteentjes) werden verricht.

Een houtmonster van een van de grote balken werd door de botanicus JoHN BEARD ter onderzoek opgezonden aan S. J. RECORD. Het bleek Demerara Greenheart te zijn! Hetgeen pleit voor de veronderstelling van BEARD dat de Martello Tower niet van Spaans, maar van Brits makelij is, niet gebouwd vóór 1700, maar pas laat in de $18 \mathrm{e}$ of in het begin van de $19 \mathrm{e}$ eeuw. ${ }^{1}$ )

\section{MOURERA FLUVIATILIS, EEN SIERAAD VAN DE SURINAAMSE VALLEN}

Even benoorden Kabel tuimelt het water van de Suriname-rivier, tussen muren van groen, over een aantal granieten drempels oceaanwaarts,

De Aloesoebanja-vallen op 1 September 1955: Een onvergetelijk beeld! Niet het minst door de onverwachte bloemenpracht welke de, bij lage waterstand uit de stroomversnelling opstekende rotspartijen een rose gloed geeft. Een treffende kennismaking met Mourera fluviatilis Aublet (fig. 6-9) ${ }^{2}$ ), de grootste vertegenwoordiger van de Podostemaceae ${ }^{3}$ ), een plantenfamilie welke uitsluitend in snelstromende gedeelten van vele tropische rivieren in Amerika, Afrika, Azië en Australië wordt gevonden.

Er komen nog twee andere, veel minder opvallende Podostemaceae in de Aloesoebanja-vallen voor: Apinagia versteeghi (Went) van Royen, slechts enkele centimeters groot, en $A$. pilgeri Mildbread, die niet groter wordt dan acht millimeter. $\mathrm{Zij}$ vormen ruige overtrekken op het gladgeschuurde rotsoppervlak. De kleinste soort, Castelnavia pusilla uit Centraal Brazilië, bereikt slechts de grootte van enkele millimeters, terwijl de bloemen uit een korstmos-achtige basis ontspringen.

1) SAmuel J. Record: Notes on tropical timbers. Trop. woods $8 I$, 1945, p. 2-4. (p. 2: Greenheart in the Martello Tower on Barbuda). - Report on Barbuda by dr BEARD ... to Director of Agriculture, Antigua, dd. 30 April 1945, 9 pp. getijpt, met kaarten.

2) De bijschriften van de foto's zijn van de hand van dr P. van ROYEN.

3) Belangrijkste literatuur: L. R. Tulasne: Monographia Podostemacearum, Arch. Mus. hist. nat. 6, 1852. P. van Royen: The Podostemaceae of the New World, I, diss. Utrecht 1951, Meded. Bot. Mus. Herb. Utrecht ro7; II, Acta bot. neerl. 2, 1953 (Meded. II5); III, Acta 3, 1954 (Meded. II9). 


\section{DE ,OLD DUTCH CHURCH" VAN ST. CROIX}

Dicht bij Frederiksted, in het zuidwestelijk deel van St. Croix (U. S. Virgin Islands), te midden van de suikerrietvelden, wordt men verrast door een monumentale oprijlaan, aan het eind waarvan - achter kruiden, struiken en jong geboomte - een merkwaardig gebouw schuil gaat. Het is het landhuis Whim, een langwerpig gebouw met afgeronde smalle zijden, omgeven door een mansdiepe sleuf die als een ringvormige regenbak in de grond is ingemetseld (fig. 10-11).

Hoewel door velen ,,the old Dutch church" genoemd, is het - voor zover kan worden nagegaan - nooit iets anders dan een woonhuis geweest, ofschoon er bij bepaalde gelegenheden ook wel diensten in zullen zijn gehouden, zoals in zovele oude landhuizen op de plantage gebeurde.

De oorspronkelijke naam - voor het eerst in 1744 genoemd schijnt ,John's Rest” te zijn geweest. Het was in de Deense tijd een gewone plantage, 150 Deense acres groot, ter waarde van ongeveer 300 Rix dollar, waarvan DANIEl MARKUE eens als eigenaar wordt genoemd. In 1803 wordt er gesproken van ,Whimy”. In 1814 heette het, als bezit van Elisabeth Frances LeNNINGTON HeYliger, ,Whim”.

Wanneer het huis werd gebouwd, weten wij niet. Het zou kunnen zijn dat de eerste Moravische zendelingen de bouwers waren; zij kwamen in 1734 op St. Croix en moesten veelal handenarbeid verrichten om in hun onderhoud te voorzien. Het bouwen van een groot landhuis was - in deze tijd van goedkope arbeidskrachten (slaven) - gewoonlijk het eerste wat men deed nadat men een stuk land in eigendom had verkregen. Misschien waren zij het, die nieuwe denkbeelden brachten in de huizenbouw - die dit huis de ronde zijden gaven welke aan een kerk doen denken.

In 1767 was er op Whim een suikermolen welke door een paard werd bewogen; in 1863 kwam er een windmolen. Later deed de stoommachine zijn intrede. Een zekere LATIMER was toen de eigenaar.

Wat de naam betreft, komt men niet veel verder dan de gissing dat ,John's Rest" moest plaatsmaken voor de bijnaam ,Whim" (gril, fantasie), vanwege de indruk welke de ongewone vorm van dit huis op de eilandbewoners maakte.

Whim zal waarschijnlijk kunnen worden gerestaureerd! In het Annual Report I954 van het St. Croix Museum Inc. geeft de directeur van dit museum, CYRIL L. MARSHALL - van wie de boven- 


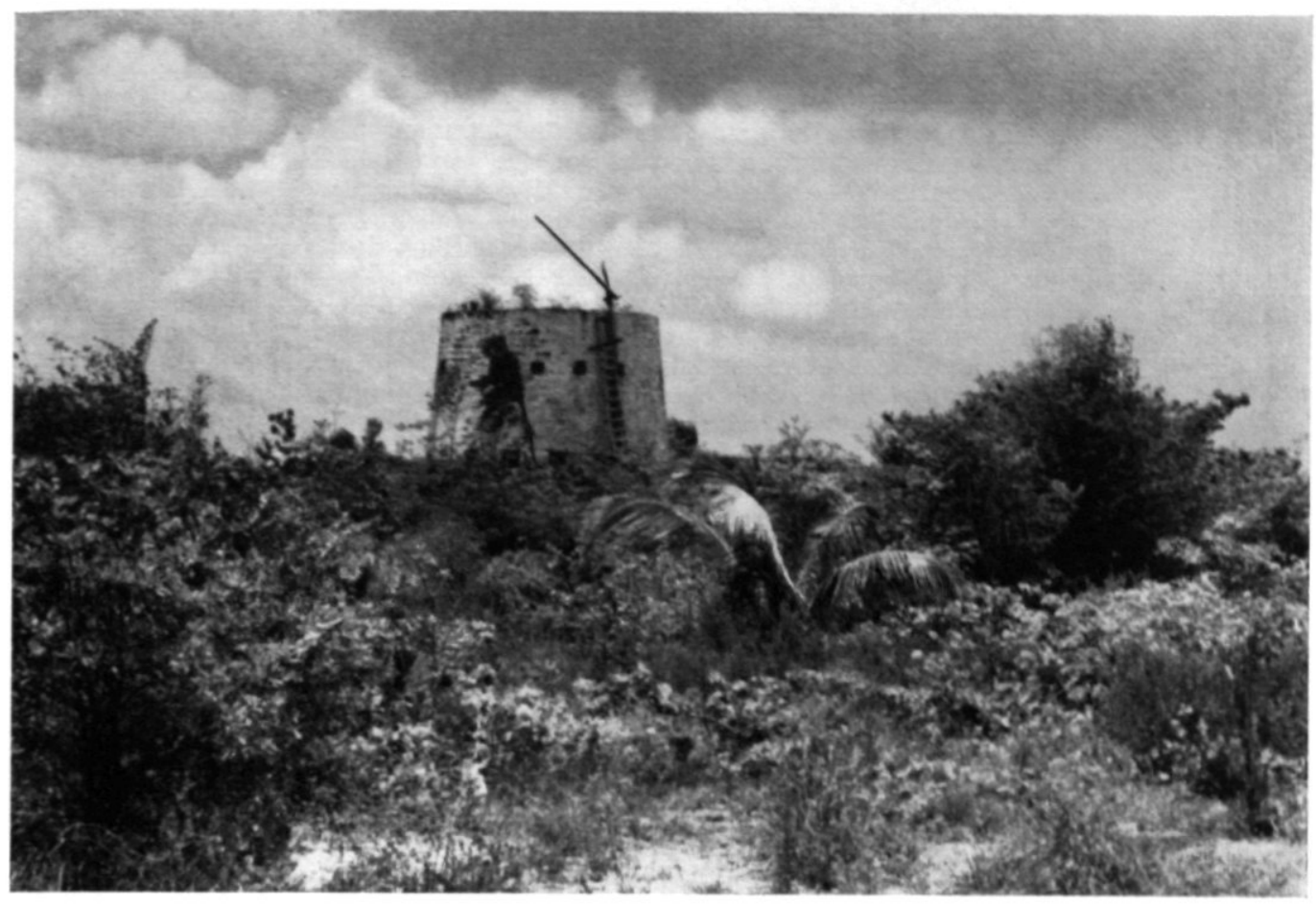

Fig. 4. De Martello Tower op $\mathrm{B}$ a r bu d a, van de zeezijde gezien, half schuil gaande achter de jonge strandvegetatie (op de voorgrond) en de oudere begroeiing.

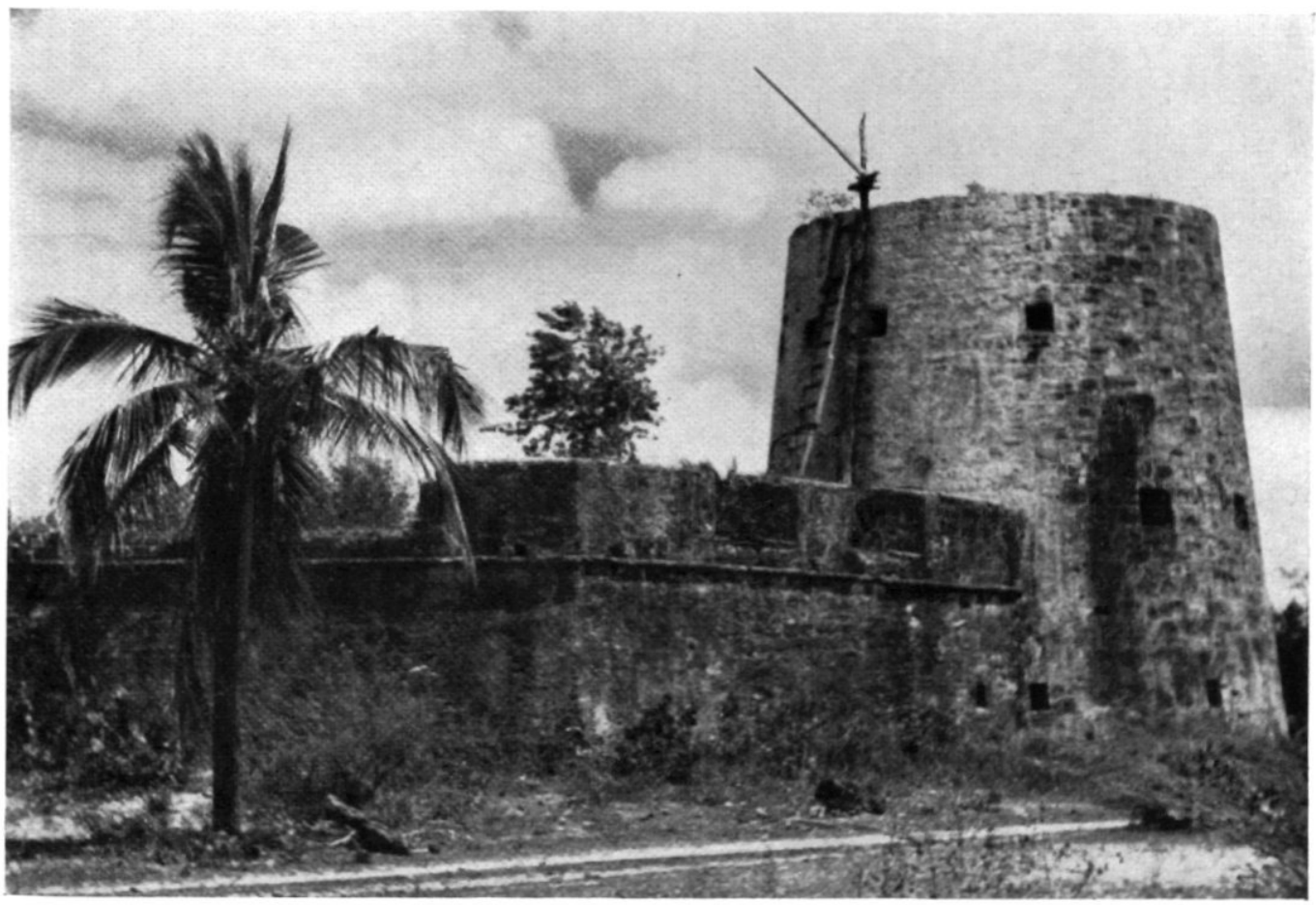

Fig. 5. De Martello Tower met de zware kantelen aan de zeezijde. 
Fig. 6-7. Mourera fluviatilis op de granietrotsen van de Aloesoebanjavallen bij Kabel, S u r i n a m e. - Door hechtschijfjes of door middel van de gehele wortel die zijn functie voor voedselopname geheel gewijzigd heeft en bladgroen bevat, hechten de planten zich aan rotsblokken of vast gesteente en weerstaan daardoor het geweld van het water. Gewoonlijk zijn zij geheel door het water bedekt en vormen dan alleen bladeren, maar zodra zij aan de lucht worden blootgesteld begint de bloei, die binnen 24 uur tot rijpe zaden leiden kan. - Mourera fluviatilis kan tot 3 meter lange bladeren vormen, terwijl de bloeiwijze een tot 80 centimeter lange twee-zijdige aar is. - Fig. 8-9, op volgende bladzijde. De bloemen van de meeste podostemaceën zijn in hun jeugd beschermd door een dunvliezig omhulsel dat tijdens de bloei de basis van de bloemsteel omgeeft. Bij de soorten waar dit hulsel ontbreekt zijn de bloembladen duidelijk en omhullen deze de

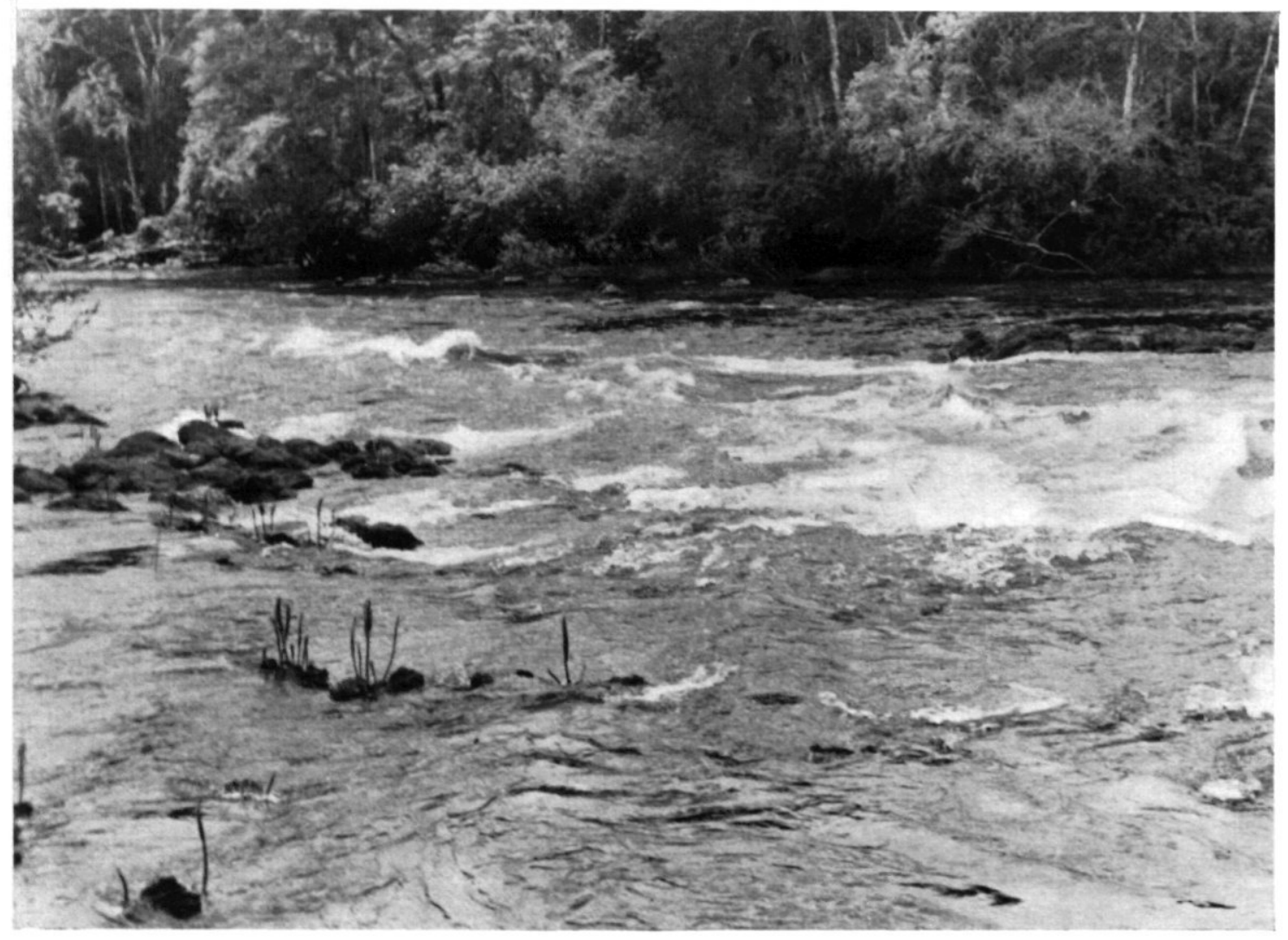


meeldraden en het vruchtbeginsel. Bij de andere soorten echter zijn de bloembladen gereduceerd tot kleine tandjes, tussen de meeldraden in. Het vruch tbeginsel is over het algemeen twee-hokkig en draagt twee korte stijlen. De vruchten springen bij rijpheid open op de tussenschotten en laten een groot aantal zeer kleine zaden vrij. Over de wijze waarop deze zaden worden verspreid is nog weinig met zekerheid bekend. - De bladeren zijn door de sterke stroom langs de randen geheel ingescheurd. De bovenkant is door de tot 10 centimeter hoge, harde aanhangsels grillig van uiterlijk. Evenals de kleine bundels haren op de bladeren van andere podostemaceën-soorten dienen deze uitsteeksels vermoedelijk tot een vergroting van de mogelijkheid van stofwisseling. De kleur van de bladeren is opvallend groen, in enkele gevallen roodachtig. Soms gebruikt men de bladeren als veevoeder, Na verbranding geven zij zout.

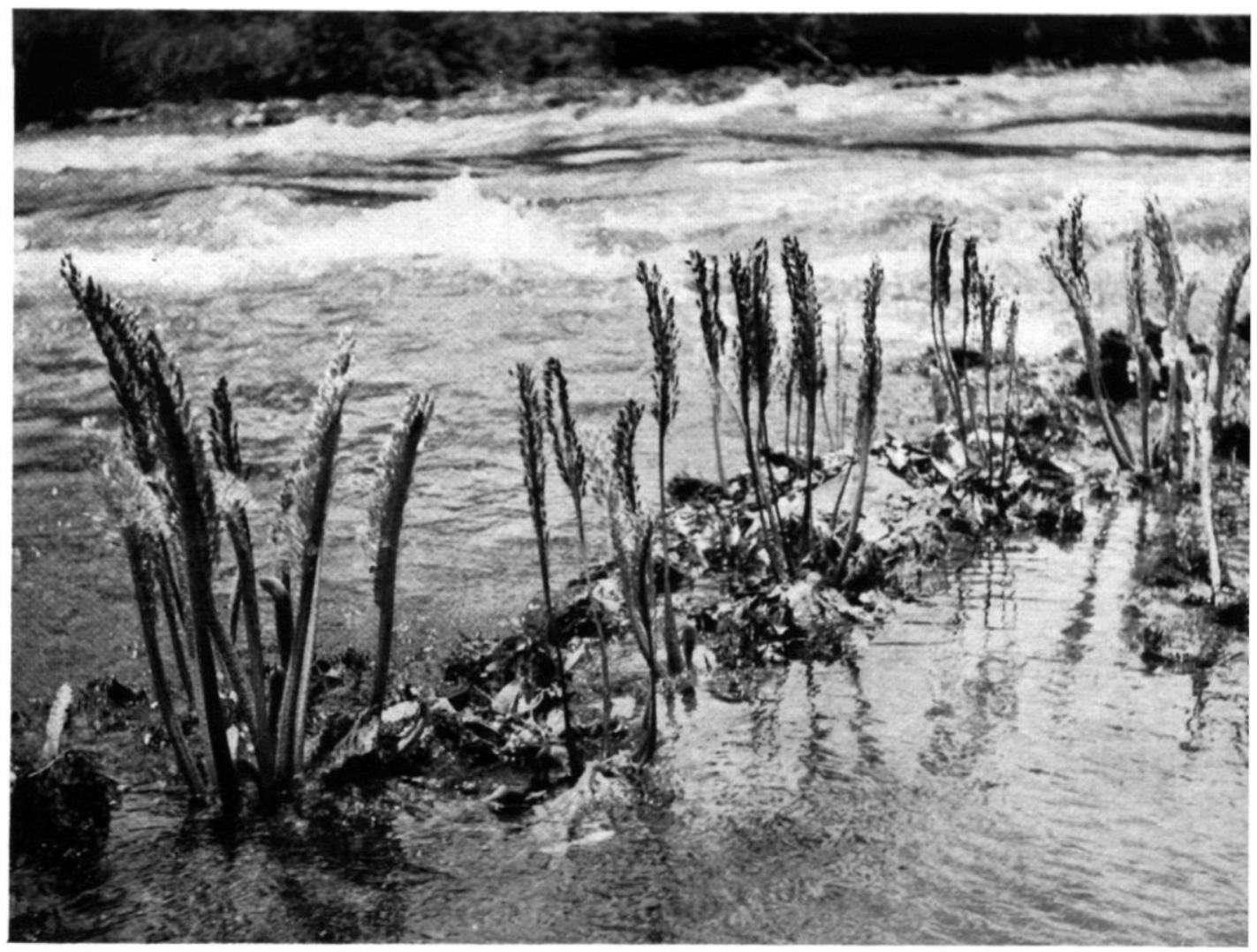



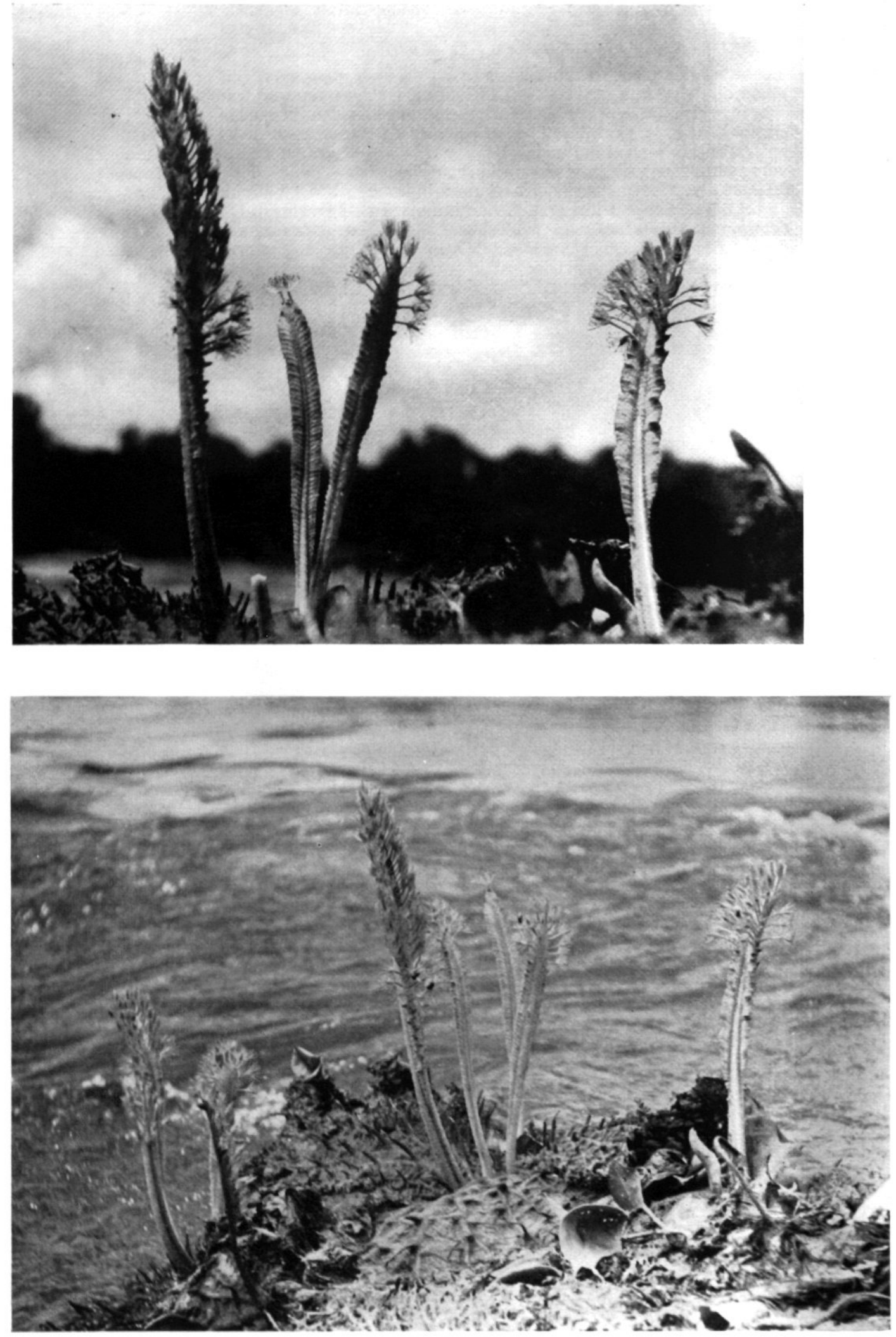

Fig. 8-9. Mourera fluviatilis op de rotsen van de Aloesoebanja-vallen. Bijschriften op vorige bladzijde. 
staande historische gegevens afkomstig zijn! — enkele beschouwingen, die de hoop rechtvaardigen dat deze „Old Dutch Church” zal kunnen worden bewaard.

\section{MENSENFIGUURTJES ALS ROTSTEKENING OP BONAIRE}

In de vele rotstekeningen op Aruba heeft reeds MARTIN ${ }^{1}$ ), in 1885 , enkele mensengestalten menen te herkennen. PINART ${ }^{2}$ ) gaf in 1890 schetsen die de lezer van zijn geschrift niet in twijfel laten - al moet erkend worden dat de betreffende petrographieën voor de hedendaagse, critische beschouwer minder overtuigend zijn.

A. D. RingmA ${ }^{3}$ ) ontdekte in 1949 op Curaçao een uitgehouwen figuur, welke zeer waarschijnlijk een gelaat met hoofdtooi voorstelt.

Maar van de rotswanden van Bonaire waren geen mensenbeelden bekend - als men afziet van sterk gestyleerde figuren of symbolen zoals zij ook op de andere eilanden gevonden worden tot op 14 April 1955,'toen de zaklantaarns van fotograaf K. MAYER en schrijver dezes de ,,poppetjes" belichtten die men hierbij vindt afgebeeld (fig. 12-14).

Dat de vinders in hun geestdrift dachten aan een balletscène moge door nuchterder beschouwers worden vergeven.

Laat de vindplaats voorlopig nog een geheim blijven; er is op dit gebied al zo ontzaggelijk veel geschonden!

\section{S U M M A R Y}

\section{CARIBBEAN PICTURES (I-V)}

I. HUT WITH GRINDING STONE ON ARUBA (Fig. 1-3, 15-16)

Description of an old hut, to be found in Rooi Arikok, and of a grinding stone: The piedra di mula consisting of quartzdiorite, the manga being a piece of coral. (May 5th, 1955).

1) K. MARTIN : De Nederlandsche expeditie naar de West-Indische eilanden en Suriname 1884-1885. Tijdschr. Ned. Aardr. Gen. (2) 2 Versl. 1885 (p. 356).

2) A. L. Pinart: Aperçu sur l'ile d'Aruba ..., 1890.

3) P. WagenaAR Hummelinck: Rotstekeningen van Curaçao, Aruba en Bonaire. W. I. Gids 34, 1953 (p. 11, 25, fig. 20-21). 


\section{THE MARTELLO TOWER ON BARBUDA (Fig.. 4-5)}

A fort of unknown origin on the south shore of Barbuda (North of Antigua), about 40 feet high, with three stories of loopholes, and a redoubt about 20 feet square and 10 feet high on the south side. The building is of sandstone, and still contains some decaying woodwork. - A specimen of the wood has been identified as Demerara Greenheart, which confirms the supposition that the Tower is of British construction and dates from the late 18 th or early 19 th century. (July 8 th, 1955).

III. MOURERA FLUVIATILIS: A FLORAL TRIBUTE TO THE SURINAM RAPIDS

(Fig. 6-9)

Some data on Mourera fluviatilis Aublet, flowering in the Aloesoebanjarapids, Suriname Rivier, near Kabel - one of the three species of Podostemaceae which are known from this locality. (September 1st, 1955).

$$
\text { IV. THE OLD DUTCH CHURCH OF ST. CROIX (Fig. 10-11) }
$$

The original name of Whim estate - commonly also known as the Old Dutch Church - appeared to be John's Rest, recorded as early as 1774 . In 1803 the title of this Danish estate was recorded as Whimy; in 1814 the name seems to have become Whim. Conjectures on the name Whim usually have it that the unusual shape of the house was the owners' whim (fancy). - There is no record of just when the house was built, but it may be presumed that is was done by early Moravian missionaries who came to St. Croix in 1734, and who often did manual work to earn their keep. They may have given the rounded ends which have always suggested a church. (June 10th, 1955).

V. ROCK DRAWINGS REPRESENTING PLAYFUL FIGURES ON BONAIRE

(Fig. 12-14)

Pictures of some petrographs - probably representing human figures - put on with a brownish-red pigment, on a dripstone cave wall. The „puppets" are, from left to right, about 29, 16, 30, and $15 \mathrm{~cm}$ high. (April 14th, 1955). 

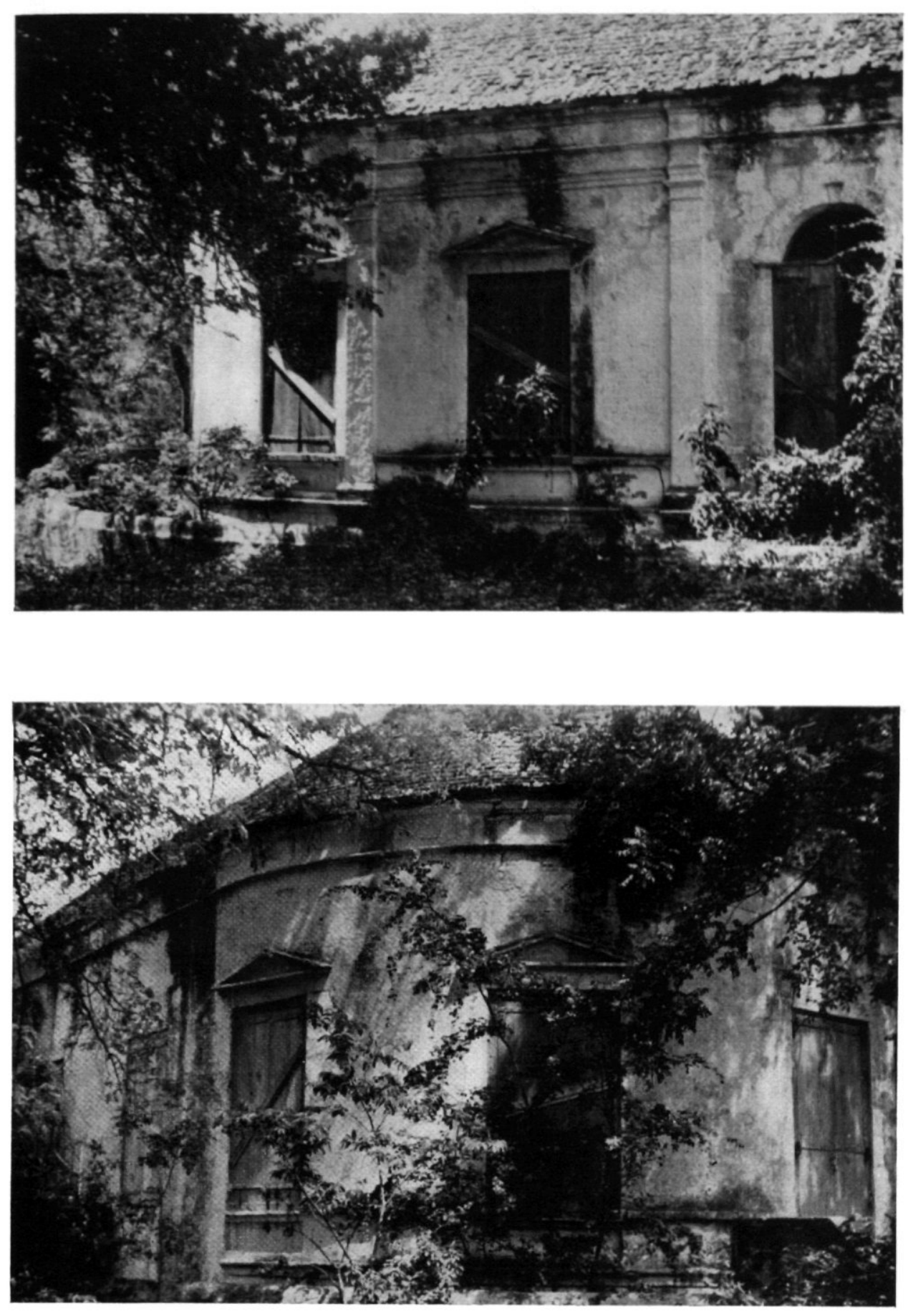

Fig. 10-11. Whim, een merkwaardig oud gebouw op St. Croix, dat de ,Old Dutch Church” wordt genoemd. 


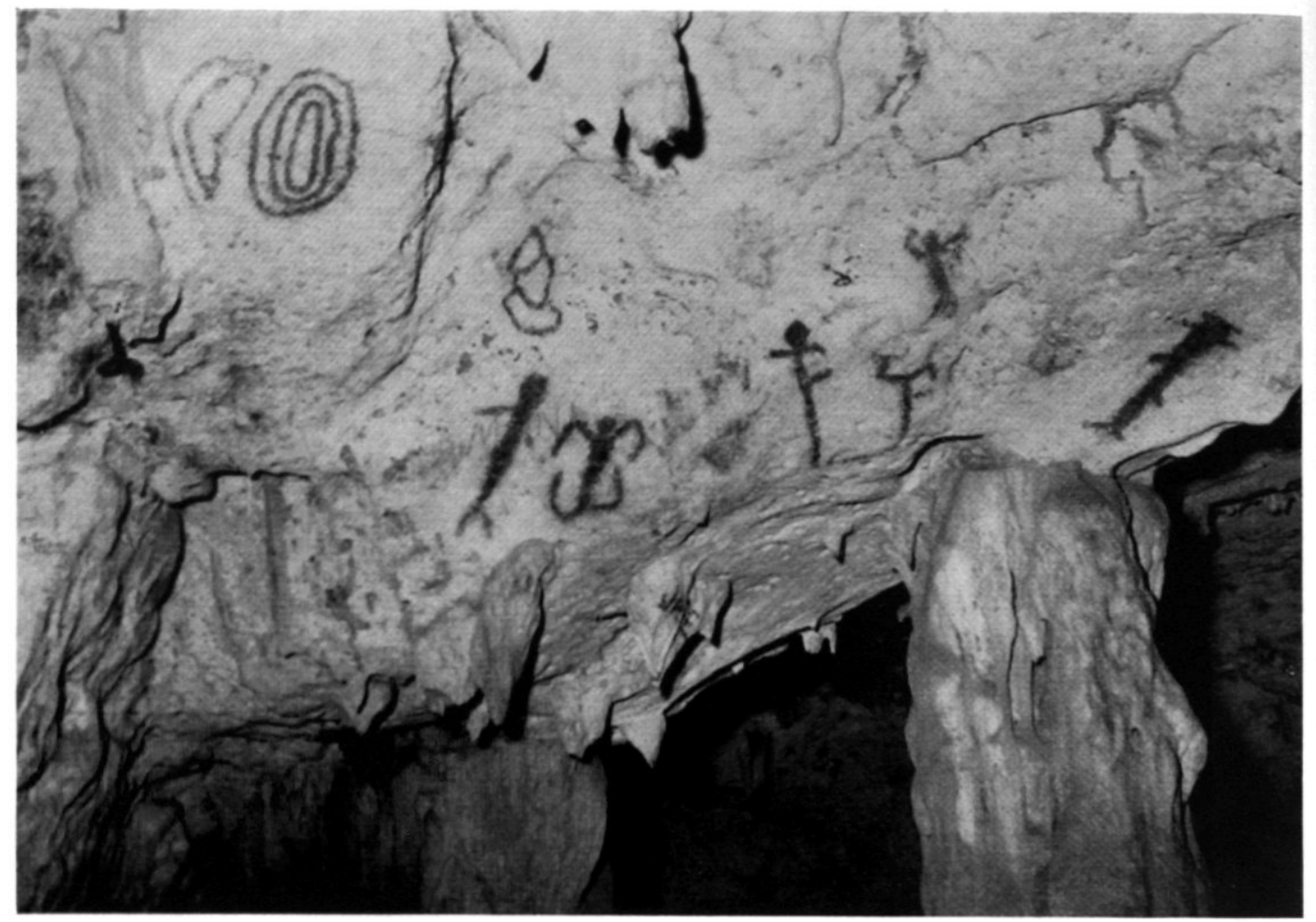

Fig. 12-14. Een ,,balletscène" van roodbruine figuurtjes op de blanke druipsteenwand van een grot op B o n a i r e. De ,,poppetjes" zijn, van links naar rechts, achtereenvolgens $29,16,30$ en 15 centimeter hoog.
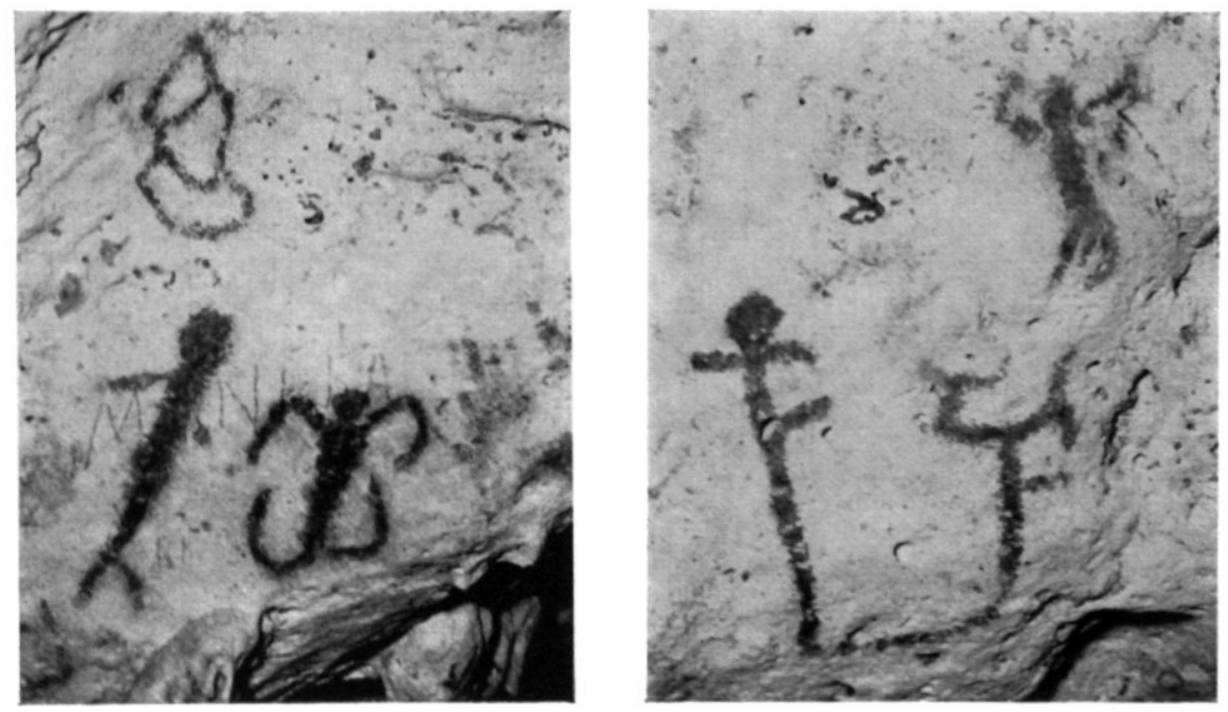